\title{
Colorimetric analysis of outdoor illumination across varieties of atmospheric conditions
}

\author{
Shahram Peyvandi, ${ }^{1, *}$ Javier Hernández-Andrés, ${ }^{2}$ F. J. Olmo, ${ }^{3}$ Juan Luis Nieves, ${ }^{2}$ and Javier Romero ${ }^{2}$ \\ ${ }^{1}$ Department of Psychology, Rutgers, The State University of New Jersey, Newark, New Jersey 07102, USA \\ ${ }^{2}$ Department of Optics, Sciences Faculty, University of Granada, Granada 18071, Spain \\ ${ }^{3}$ Department of Applied Physics, Sciences Faculty, University of Granada, Granada 18071, Spain \\ ${ }^{*}$ Corresponding author: peyvandi@psychology.rutgers.edu
}

Received 8 February 2016; revised 9 April 2016; accepted 10 April 2016; posted 11 April 2016 (Doc. ID 259168); published 0 MONTH 0000

\begin{abstract}
Solar illumination at ground level is subject to a good deal of change in spectral and colorimetric properties. With an aim of understanding the influence of atmospheric components and phases of daylight on colorimetric specifications of downward radiation, more than 5,600,000 spectral irradiance functions of daylight, sunlight, and skylight were simulated by the radiative transfer code, SBDART [Bull. Am. Meteorol. Soc. 79, 2101 (1998).], under the atmospheric conditions of clear sky without aerosol particles, clear sky with aerosol particles, and overcast sky. The interquartile range of the correlated color temperatures (CCT) for daylight indicated values from 5712 to $7757 \mathrm{~K}$ among the three atmospheric conditions. A minimum CCT of $\sim 3600 \mathrm{~K}$ was found for daylight when aerosol particles are present in the atmosphere. Our analysis indicated that hemispheric daylight with CCT less than $3600 \mathrm{~K}$ may be observed in rare conditions in which the level of aerosol is high in the atmosphere. In an atmosphere with aerosol particles, we also found that the chromaticity of daylight may shift along the green-purple direction of the Planckian locus, with a magnitude depending on the spectral extinction by aerosol particles and the amount of water vapor in the atmosphere. The data analysis showed that an extremely high value of CCT, in an atmosphere without aerosol particles, for daylight and skylight at low sun, is mainly due to the effect of Chappuis absorption band of ozone at $\sim 600 \mathrm{~nm}$. In this paper, we compare our data with well-known observations from previous research, including the ones used by the CIE to define natural daylight illuminants. () 2016 Optical Society of America
\end{abstract}

OCIS codes: (330.1710) Color, measurement; (330.1730) Colorimetry; (010.1290) Atmospheric optics.

http://dx.doi.org/10.1364/JOSAA.99.099999

\section{INTRODUCTION}

The foundations of the rigorous study of the solar spectral radiation were laid down in the early decades of the nineteenth century when devices for spectral irradiance measurement began to be developed and the requirements for initiating investigation of the spectral characteristics of global irradiance in different atmospheric conditions were satisfied. One of the earliest measurements of spectral daylight was reported by Abbot et al. [1] and Taylor and Kerr [2].

The color and spectral properties of daylight are subject to substantial variations across different atmospheric conditions and phases of daylight. In 1964, Judd et al. [3] investigated 622 irradiance spectra measured in Ottawa [4], Enfield [5], and Rochester [6], with the aim of identifying representatives of various phases of natural daylight. Based on linear combinations of basis vectors, the study resulted in the CIE standard illuminants at different correlated color temperature (CCT) [7]. This characterization suffers mainly from a few numbers of observation and sites of measurement. Definition of standard CIE illuminants from a few sets of data measured in particular locations of the globe became controversial at the time, especially when analysis of natural daylight measured in Japan [8], India [9], South Africa [10], and Australia [11] showed deviations from the CIE daylight sources. In 2001, HernándezAndrés et al. [12] analyzed 2600 daylight spectra, with CCTs from 3758 to $34,573 \mathrm{~K}$, measured in Granada, Spain. The most frequent color temperature in the range of 175-180 mired, mainly observed for daylight in Granada, was found to be greater than the $r$ CCT of 154 mired, recommended by CIE for the D65 illuminant of neutral daylight. (In this research, we represent color temperature in reciprocal mega-Kelvin, a scale that is more uniformly relatable to the difference in chromaticity [13]. Reciprocal mega-Kelvin in mired $\left[\mathrm{MK}^{-1}\right]$ is denoted here by $r$ CCT, $10^{6} / \mathrm{CCT}$.) Hernández-Andrés et al. [12] also argued the generality of linear estimation of Judd et al. [3] daylight spectra as being limited to particular atmospheric conditions. 
Over many years, however, observations have been made in several locations of the globe aiming to characterize the elements of solar illumination under different atmospheric conditions. The location, spectral range, number of observations, and typical range of some well-known measurements of skylight and daylight are summarized in Table 1. Observations from previous research listed in Table 1 showed a range of $r$ CCT from $\sim 29$ to 283 mired for daylight and that from $\sim 0$ to 263 mired for skylight. Note that an observation of skylight radiation practically depends on specifications of the measurement, including the field of view (FOV) and the sun position relative to the sky region from which the observation is obtained. Therefore, in previous research, various ranges of color temperature observed for skylight are partly due to the method of measurement. Furthermore, daylight chromaticities mostly observed in the Northern Hemisphere $[5,6,12,14]$ tend to reside mainly above the Planckian locus toward the green rather than the purple side, while some observations mostly conducted in the Southern Hemisphere showed chromaticities in both directions [9-11]. To the best of our knowledge, it is still not very well known as to why the green-purple shift occurs, although the variety of the local terrain and vegetation in both measurement sites suggests that the shift may not be due to the albedo effect. Nevertheless, research by Middleton [15], Dixon [11] commented that green-purple shift may partly be explained by the effect of ground color in an overcast condition.

Considering the wide variations in spectral solar illumination, the main question is, "To what extent does natural solar irradiance vary across plausible range of atmospheric conditions and phases of daylight?" Obvious issues in addressing this question not only pertain to a huge variability of atmospheric conditions but also to the fact that a specific condition might rarely occur in selected regions of observation. Thus, a direct answer to this question obtained by measuring solar spectra in all climatological regions and seasons seems to be impractical. We have dealt with this issue by incorporating plausible atmospheric parameters into a model in which solar illumination is estimated from factors such as solar elevation, cloud cover, and the presence of aerosol particles in the atmosphere. The main goal of this research is to identify colorimetric properties of solar irradiance across a wide range of atmospheric patterns and find out how climatological parameters influence the colors of natural illuminations. To carry out computation for a given atmospheric condition, we used the radiative transfer module, SBDART [16], a discrete-ordinate algorithm of multiple scattering in plane-parallel media [17]. Although, the model proved its efficiency in solving the radiative transfer equation, observations and interpretation should be viewed with caution at higher solar zenith angles, due to several limitations on plane-parallel geometry. The SBDART code takes inputs of the single scattering albedo, vertical optical depth, and asymmetry factor in aerosol particles. The model also includes the surface albedo, cloud cover, and solar geometry. The outputs of the model, taken in this research, are the spectra for the global downward (BOTDN) and the direct solar flux (BOTDIR) at ground level. Simulation in this work was performed spectrally and resolved at wavelengths from 300 to $1,100 \mathrm{~nm}$, with $5 \mathrm{~nm}$ intervals.

This paper is organized as follows: First, we introduce related terminologies and the description of parameters selected to simulate spectral irradiance functions in Section 2. Then, the simulated spectral functions are analyzed in terms of illuminance, CCT, and chromaticity coordinates in Section 3. In Section 4, we specifically focus on the influence of components of atmospheric conditions on the colorimetric characteristic of outdoor illuminations. We also discuss the reason for the green-purple shift in daylight chromaticities. To make our simulation well relatable to direct observation, we frequently compare the results of our simulations with previously observed measurements.

\section{SIMULATING SOLAR-SPECTRAL IRRADIANCE}

Solar energy received by the Earth is categorized into components of sunlight and skylight radiation. Sunlight is the direct

Table 1. Summary of Previous Studies on Daylight and Skylight Observations ${ }^{a}$

\begin{tabular}{|c|c|c|c|c|}
\hline Ref. & Range & Type & No. & $\mathbf{M K}^{-1}$ \\
\hline [6] & & skylight & 60 & $104-127$ \\
\hline \multirow{2}{*}{ [5] } & & total sky, no sun & & $50-190$ \\
\hline & & total sky, with sun & & $140-200$ \\
\hline [4] & $300-720$ & total sky, and north sky & 99 & $25-200$ \\
\hline \multirow{2}{*}{ [10] } & & skylight, no sun & & $110-190$ \\
\hline & & south sky & & $86-190$ \\
\hline [9] & $300-700$ & north sky & 187 & $50-250$ \\
\hline$[31]$ & $300-700$ & north sky & 60 & $0-143$ \\
\hline \multirow[t]{2}{*}{ [11] } & $280-2800$ & daylight & $290+240$ & $150-190$ \\
\hline & & skylight & & $50-150$ \\
\hline
\end{tabular}

\footnotetext{
${ }^{a}$ The table shows the spectral range in nanometers, measurement type, total number of measurements (No.), and observed range of the inverse CCT in mired.
} 


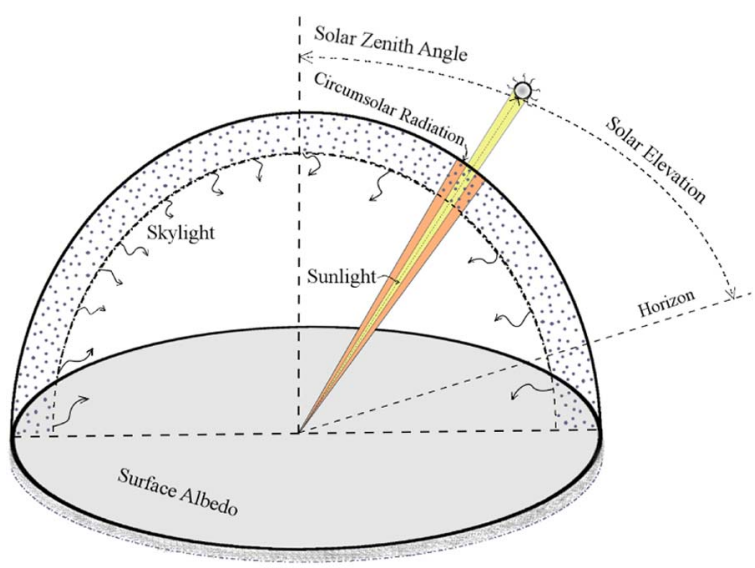

F1:1 Fig. 1. Schematic illustration of the Earth-Sun geometry and differF1:2 ent components of the solar radiation.

solar radiation at ground level, and skylight is the diffuse radiation scattered through the atmosphere from the sky as well as from the areal albedo of the reflective surrounding region. The total radiation reaching the ground is called the global radiation of daylight. The daylight spectral radiation refers to the spectrum of sunlight plus skylight. The Earth-Sun geometry and different components of solar radiation are schematically illustrated in Fig. 1. In our spectral-irradiance simulation, the global downward flux (BOTDN) refers to hemispheric daylight [12], which includes both the downward direct flux (BOTDIR) and skylight radiation. Thus, the spectrum of skylight irradiance is calculated by subtracting the BOTDIR from the corresponding BOTDN at each wavelength, Skylight $=$ BOTDN - BOTDIR . Therefore, the skylight radiation in this study totally excludes direct sunlight, similar to an observation made within a narrow FOV, extended away from the Sun's apparent position in the sky.

Table 2 summarizes the selected parameters of the SBDART code for simulating spectral-irradiance of solar illumination under three different atmospheric conditions of clear sky without aerosol particles, clear sky including aerosol particles, and overcast sky. Although a clear sky without aerosol particles is not a common atmospheric condition, it does represent a theoretical limit of the solar irradiance at ground level. In our simulation of an atmosphere with aerosol particles, the wavelength dependence of the aerosol extinction is based on a power law function with an exponent of abaer. The downward solar radiation is influenced by atmospheric transmittance depending on the effective beam path-length in the atmosphere. The solar beam path-length through the spherical curvature of the atmosphere increases with increasing the solar zenith angle (sza) [18]. In this research, 30 different values of sza, ranging from $0^{\circ}$ to $89^{\circ}$ with an interval of $5^{\circ}$ from $0^{\circ}$ to $75^{\circ}$ and an interval of $1^{\circ}$ from $76^{\circ}$ to $89^{\circ}$, were considered for simulating the solar irradiance functions. Because the rate of change in colorimetric characteristics of downward radiation is higher during twilight, we selected a finer interval of $1^{\circ}$ at zenith angles of more than $75^{\circ}$. The values for the parameters listed in Table 2 were selected to cover a range of atmospheric conditions that may commonly occur in nature. To achieve a realistic result, we frequently compare the simulation with previously observed data

Table 2. SBDART Parameters for Simulating Spectral Irradiance of Solar Radiation Over Three Different Atmospheric Conditions of Clear Sky Without Aerosol Particles, Clear Sky with Aerosol Particles, and Overcast Sky ${ }^{a}$

\begin{tabular}{|c|c|c|c|c|}
\hline Condition & No. & Paramet. & Description & Values \\
\hline $\begin{array}{l}\text { Clear Sky } \\
\text { w/o Aerosol }\end{array}$ & 16,800 & albcon & Surface albedo $^{b}$ & $\begin{array}{c}0.05,0.10,0.15,0.20,0.25,0.30,0.40,0.50,0.60 \text {, } \\
0.90\end{array}$ \\
\hline \multirow{3}{*}{$\begin{array}{l}\text { Clear Sky } \\
w / \text { Aerosol }^{c}\end{array}$} & \multirow{3}{*}{$4,838,400$} & uw & Water vapor & $0.25,0.5,1,1.5,2,2.5,3,4$ \\
\hline & & albcon & Surface albedo $^{b}$ & $0.05,0.10,0.20,0.30,0.5,0.9$ \\
\hline & & uw & Water vapor & $0.25,0.5,1,1.5,2,2.5,3,4$ \\
\hline \multirow{11}{*}{$\begin{array}{l}\text { Overcast } \\
\text { Sky }\end{array}$} & \multirow{11}{*}{756,000} & wlbaer & Wavelength of aerosol spectral dependence & 0.55 \\
\hline & & wbaer & Single scattering albedo of BLA at wlbaer & $0.6,0.7,0.8,0.95,1$ \\
\hline & & gbaer & Asymmetry factor of BLA at wlbaer & $0.5,0.6,0.7,0.8,0.9,1$ \\
\hline & & tbaer & Vertical optical depth of BLA & $0.01,0.1,0.2,0.3,0.5,0.8,1$ \\
\hline & & abaer & Ångström exponent & $0.0,0.5,1.0,2.0$ \\
\hline & & albcon & Surface albedo $^{c}$ & 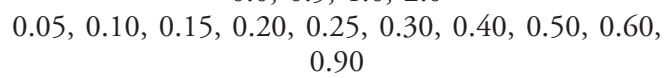 \\
\hline & & uw & Water vapor & $0.25,0.5,1,1.5,2,2.5,3,4$ \\
\hline & & uo3 & Ozone concentration & $0.20,0.25,0.30,0.35,0.40,0.45,0.50$ \\
\hline & & zcloud & Cloud layers altitude & 1 \\
\hline & & tcloud & Layers' optical depth & $0.5,1,5,10,15,50,70,100,200$ \\
\hline & & nre & Cloud drop radius & $6,10,20,30,40$ \\
\hline
\end{tabular}

${ }^{a}$ The table also shows the total number (No.) of the spectral-irradiance functions of total downward (BOTDN) and direct flux (BOTDIR) of solar radiation simulated for each condition over the spectral range 0.3-1.1 $\mu \mathrm{m}$ (BLA stands for the boundary layer aerosols).

${ }^{b}$ Spectrally uniform albedo (isalb $=0$ ).

'Power law spectral dependence set by abaer; a single value is used for each wbaer, gbaer, and tbaer at wlbaer $=0.55 \mu \mathrm{m}$. 
and select realizable range of parameters based on the available measurements on specific atmospheric components [19-22], range of CCTs reported in the literatures, and the experience of the third author in atmospheric science. Nevertheless, the simulated irradiance spectra by the parameters in Table 2 do not cover all possible instances of physical conditions, but it does provide insight into understanding influences of atmospheric components on the color of natural illumination.

\section{DATA ANALYSIS}

The characteristic of solar illumination is a matter of particular interest in color application and imaging of a natural scene [23-26]. In the following sections, we study illuminance, color temperature, and chromaticity of the simulated solar irradiance spectra.

\section{A. Luminance}

The illuminance, $E_{v}\left(\mathrm{~lm} / \mathrm{m}^{2}\right)$, of a solar spectral-irradiance function, $\boldsymbol{r}(\lambda)\left(\mathrm{W} / \mathrm{m}^{2} \mu \mathrm{m}\right)$, can be calculated by

$$
E_{v}=K_{m} \sum_{\lambda=360}^{780} \boldsymbol{r}(\lambda) V(\lambda) \Delta \lambda,
$$

where $K_{m}=683.002 \mathrm{~lm} / \mathrm{W}, V(\lambda)$ is the photopic luminosity function [27], and $\Delta \lambda=0.005(\mu \mathrm{m})$ is the sampling wavelength interval of the irradiance function. Then, the luminance, $L_{v}\left(\mathrm{~cd} / \mathrm{m}^{2}\right)$, of the solar radiation illuminating a perfect white surface is

$$
L_{v}=\frac{E_{v}}{\pi}
$$

Figure 2 shows the average, minimum, and maximum illuminance values of BOTDN simulated under the three atmospheric conditions of clear sky without aerosol particles, clear sky with aerosol particles, and overcast sky as a function of solar zenith angle. It can be observed that a maximum illuminance of BOTDN under clear sky with aerosol particles is higher than that of BOTDN under clear sky without aerosol particles, both observed at albcon $=0.9$. This is due to an increase of the diffuse component of the light by aerosol particles at a higher value of the surface albedo.

\section{B. Color Temperature}

The direct solar flux, blocked out by aerosol particles and cloud bodies, decreases drastically during twilight. Thus, before colorimetrically analyzing our data set, it is a reasonable measure to leave out negligible solar flux by defining a minimum threshold of $0.01 \mathrm{~cd} / \mathrm{m}^{2}$ on luminance. Considering spectra with $L_{v} \geq$ $0.01 \mathrm{~cd} / \mathrm{m}^{2}$ only eliminates direct solar irradiance functions with low energy across wavelengths that are mainly observed at a lower solar elevation angle in the presence of aerosol particles and clouds in the atmosphere.

With a training set of isotemperature lines from $100 \mathrm{~K}$ to $10^{5} \mathrm{~K}$ with intervals of $50 \mathrm{~K}$, the CCTs of the selected spectra were calculated using Robertson's interpolation method $[13,28]$. Thus, in this research, infinite CCT refers to an irradiance with $r$ CCT $<10$ mired, which is considered beyond the chromaticities of the Planckian locus. Figure 3 shows the average $r$ CCT of the simulated BOTDN, BOTDIR, and skylight, in an atmosphere with aerosol particles, as a function of the solar zenith angle. As presented in Fig. 3, while the rCCT of direct sunlight (BOTDIR) increases, the $r$ CCT of daylight (BOTDN) rapidly falls off at lower solar elevation angles $\left(\right.$ sza $\left.>80^{\circ}\right)$. However, $r$ CCT of skylight in an atmosphere with (and without) aerosol particles increases with sza and then falls off at sza $>80^{\circ}$. This phenomenon will be further analyzed in Section 4 . Analysis of the simulated skylight radiation showed $r$ CCT in the range of 0-98.2 mired for the clear sky without aerosol particles, 0-261.4 mired for the clear sky with aerosol particles, and 0-172.8 mired for the overcast sky. The overall range of $r$ CCT for skylight radiation in our data is in agreement with a narrow-FOV measurement of skylight made in Granada [29]. Analysis of our simulated direct sunlight radiation with $L_{v} \geq 0.01 \mathrm{~cd} / \mathrm{m}^{2}$ indicated that the $r$ CCT of sunlight falls in the range of 177-1057 mired for the clear sky without aerosol particles, 178-1591 mired for the clear sky with aerosol particles, and 156-392 mired for the overcast sky. Direct sunlight with CCT $<1000 \mathrm{~K}$ was found during twilight, which corresponds to a rare observational situation where measurement is made from the sun's entire disk at a high altitude of widely open horizon [30]. The minimum of $r$ CCT for daylight among the three conditions falls below 10 mired. In our simulation, we observed extreme values of CCT for daylight at low sun $\left(\right.$ sza $\left.>88^{\circ}\right)$ in an atmosphere with higher levels of ozone
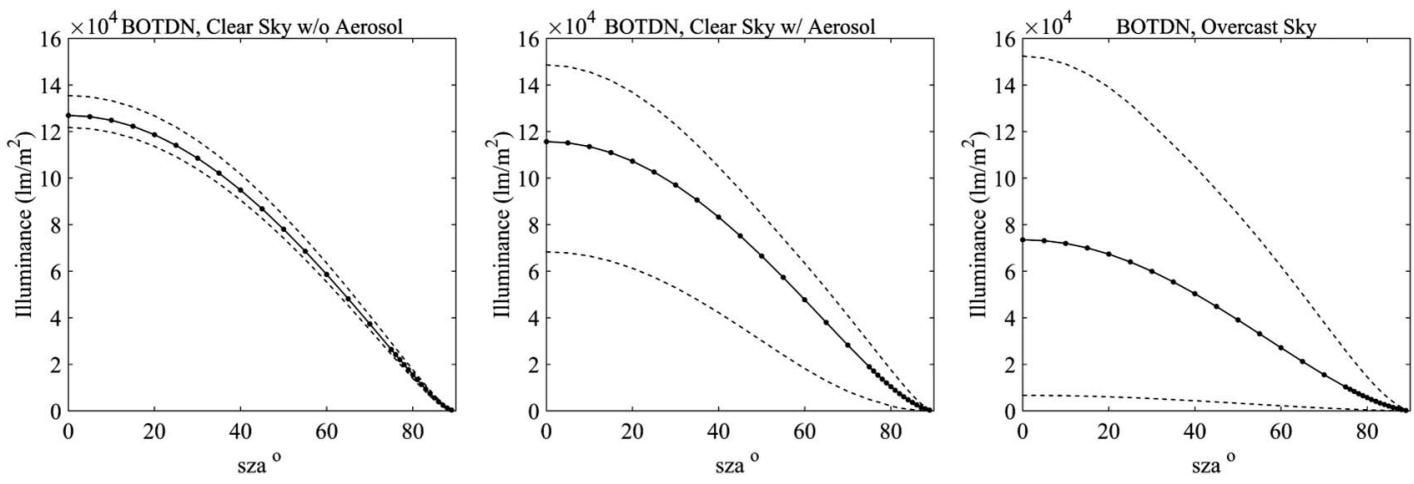

Fig. 2. Average illuminance values of hemispheric daylight (BOTDN) simulated under the atmospheric conditions of clear sky without aerosol particles, clear sky with aerosol particles, and overcast sky are presented as a function of solar zenith angle (sza ${ }^{\circ}$. In this figure, the dashed lines show the observed minimum and maximum limits of the illuminance values. 

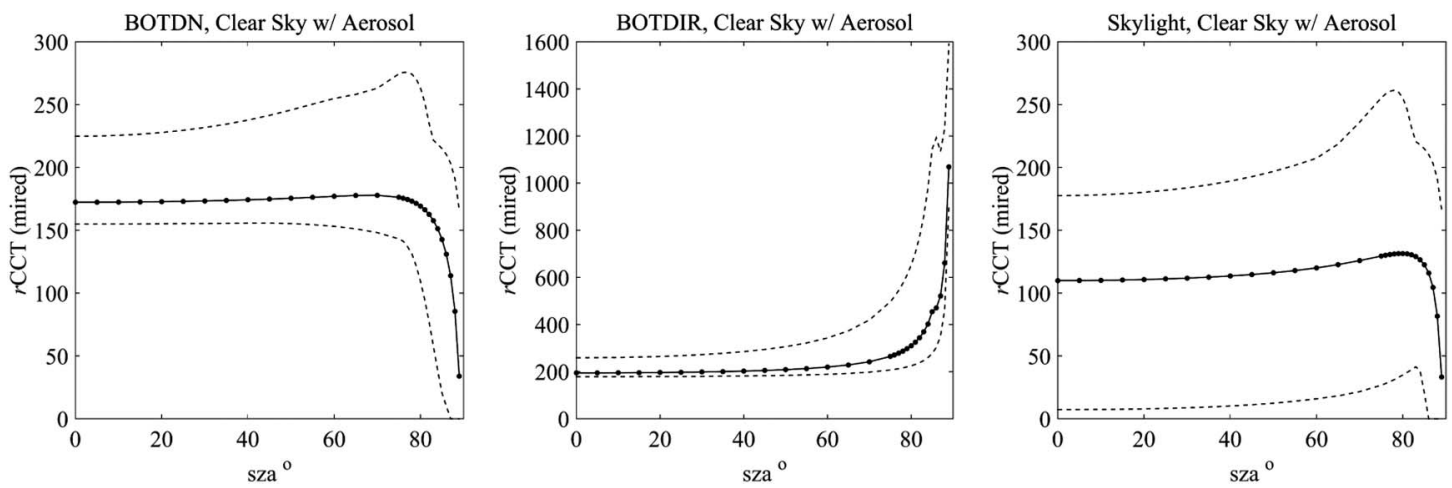

Fig. 3. Average $r$ CCT (mired) of daylight (BOTDN), direct sunlight (BOTDIR), and skylight irradiance functions simulated under the atmospheric conditions of clear sky with aerosol particles as a function of solar zenith angle $\left(s z a^{\circ}\right)$. In this figure, the dashed lines show the observed minimum and maximum limits of the $r$ CCT values.

concentration (uo3 $>0.3$ ). The maximum of $r$ CCT for daylight under a clear sky without aerosol particles is 186 mired, under the clear sky with aerosol is 276 mired, and under the overcast sky is 177 mired. As shown in Table 2, the values of the SBDART parameters were selected with somewhat uniform intervals within a given range. Thus, the histogram distribution of $r$ CCT under each atmospheric condition fairly represents the most frequent color temperature with less bias due to sampling error. We expect that such an error becomes insignificant by collecting a large set of spectral data for a particular atmospheric condition. The histograms of $r$ CCT for daylight under the three atmospheric conditions are presented in Fig. 4. Our data showed that daylight (BOTDN) under the clear sky without aerosol particles, under the clear sky with

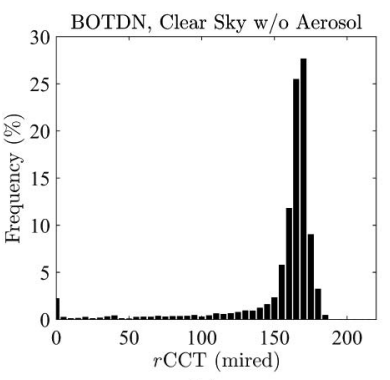

(a)

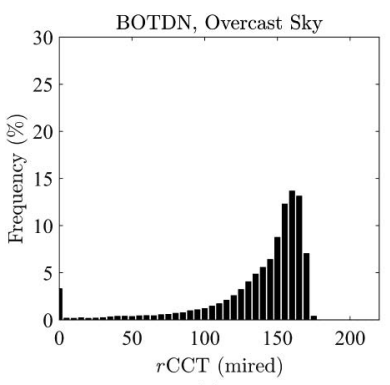

(c)

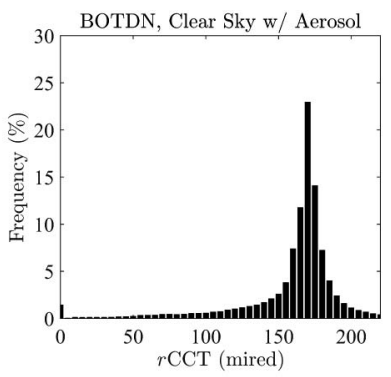

(b)

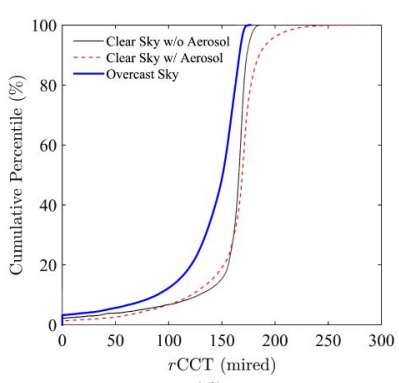

(d)
Fig. 4. Histogram of $r$ CCT for daylight (BOTDN) under the atmospheric conditions of clear sky without (a) aerosol particles, (b) clear sky with aerosol particles, (c) and overcast sky. The bin size is 5 mired wide in each histogram. (d) The plots of cumulative percentile of the $r$ CCT under the three atmospheric conditions. aerosol particles, and under the overcast sky can be characterized by the most frequent $r$ CCT observed at $\sim 163-173$ mired, 168-173 mired, and 153-168 mired, respectively. Note that the most frequent $r$ CCT for daylight under the clear sky with aerosol particles is represented by a distinct peak at 170 mired, whereas $r$ CCT for daylight under the overcast sky and the clear sky without aerosol particles show tendency toward higher CCT of more than $6000 \mathrm{~K}$. The range of most frequent CCTs observed for daylight in Boulder, Colorado, (5500-6400 K) [14] also includes values of more than $6000 \mathrm{~K}$. However, the most frequent $r$ CCT observed in Granada [12] was found in the range of $5555-5715 \mathrm{~K}$, similar to the condition of clear sky with aerosol particles. Figure 4(d) shows the cumulative percentile of $r$ CCT under the three atmospheric conditions. It can be observed that the percentiles of $r$ CCT under the clear sky without aerosol particles mainly falls between the percentiles of the clear sky with aerosol particles and the overcast sky.

To find the range containing $50 \%$ of CCT, we calculated the $25 \%$ and $75 \%$ interquartile values of CCT for each condition. The results indicated interquartile values of CCTs from $5889 \mathrm{~K}$ up to $6294 \mathrm{~K}$ in the clear sky without aerosol particles, between 5712 and $6325 \mathrm{~K}$ in the clear sky with aerosol particles, and from $6218 \mathrm{~K}$ up to $7757 \mathrm{~K}$ in the overcast sky. As shown in Figs. 3 and 4, the overcast sky and atmosphere with aerosol particles represented extreme conditions where the limits of CCT were observed. Daylight measured in Granada [12], with the mostly observed CCTs of $\sim 5555-5700 \mathrm{~K}$, falls between these two extreme conditions, inclined toward an atmosphere with aerosol particles. The recommended $r$ CCT of 154 mired for the D65 illuminant falls only in the interquartile range of CCTs for daylight in the overcast sky. The 25th, 50th (median), and 75th percentiles of $r$ CCT for the simulated daylight under the three atmospheric conditions are shown in Table 3.

\section{Chromaticity}

The CIE 1931 chromaticity coordinates of the selected irradiance functions of BOTDN, BOTDIR, and skylight with $L_{v}>$ $0.01 \mathrm{~cd} / \mathrm{m}^{2}$ were calculated. Figure 5 represents the chromaticity coordinates, $(x, y)$, plotted overlaid with the Planckian locus, separately for the atmospheric conditions of clear sky 
Table 3. 25th, 50th (median), and 75th Percentiles of rCCT (mired) for the Simulated Daylight (BOTDN) Under the Three Atmospheric Conditions of Clear Sky Without Aerosol, Clear Sky with Aerosol and Overcast Sky ${ }^{a}$

\begin{tabular}{lcccc}
\hline Condition & 25th \% & 50th \% & 75th \% & IQR \\
\hline Clear Sky w/o Aerosol & 158.9 & 166.0 & 169.8 & 10.9 \\
Clear Sky w/ Aerosol & 158.1 & 169.2 & 175.1 & 17.0 \\
Overcast Sky & 128.9 & 150.7 & 160.8 & 31.9 \\
\hline
\end{tabular}

${ }^{a}$ Last column of the table shows the interquartile range (IQR) in mired.

without aerosol particles, clear sky with aerosol particles, and overcast sky. As shown in Figure 5, $r$ CCT of daylight (BOTDN) and skylight across the three conditions can be less than 10 mired, with further chromaticity extension toward the origin of the diagram under the overcast condition. Such illuminations with chromaticities beyond the Planckian locus ( $r$ CCT $<10$ mired), particularly at low sun, were also reported in previous research $[8,31,29,32,33]$. In Section 4.A, we specifically analyze the simultaneous influence of ozone concentration and solar elevation on the color temperature. It should be noted that, as the CCT decreases, only the chromaticity points of daylight (and skylight) in an atmosphere with aerosol particles shifted toward the purple side of the Planckian locus. The chromaticity distribution of daylight measured in Granada is close to the Planckian locus with some observations toward the purples. Similar to the condition of clear sky without aerosol particles in Fig. 5, the chromaticities of daylight in Boulder, Colorado [14], are distributed above the Planckian locus. The middle column of Fig. 5 shows the chromaticities of the direct sunlight illumination (BOTDIR). Sunlight illumination covers a wide range of CCT as low as $\sim 700 \mathrm{~K}$, corresponding to the clear sky with aerosol particles, to a high value of $6386 \mathrm{~K}$, corresponding to the overcast sky. Chromaticities located in the far right-hand end of the BOTDIR diagrams were obtained during twilight when the luminance of direct flux is too low. As seen in the clear sky without aerosol particles, a group of chromaticities for direct sunlight with CCT $\sim 2000 \mathrm{~K}$ corresponds tosza $=88^{\circ}$. Increasing the zenith angle from $87^{\circ}$ and $88^{\circ}$ to $89^{\circ}$ introduced a gap in the chromaticity space indicating that the rate of change in CCT of direct sunlight is higher at low sun. The chromaticities of direct sunlight extend toward
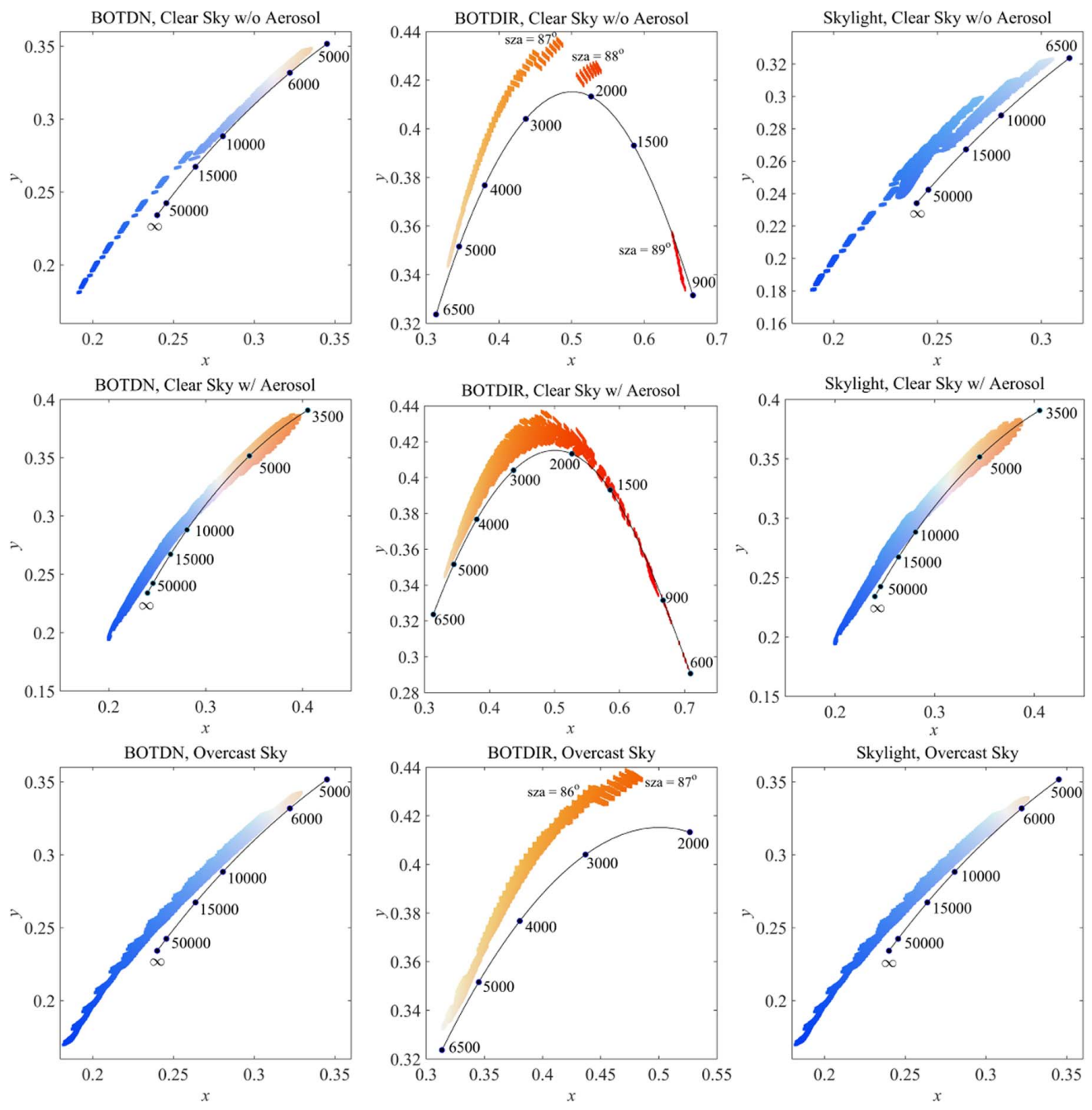

Fig. 5. CIE 1931 chromaticity diagram of daylight (BOTDN), direct sunlight (BOTDIR), and skylight irradiance functions simulated under the atmospheric conditions of clear sky without aerosol particles, clear sky with aerosol particles, and overcast sky. 


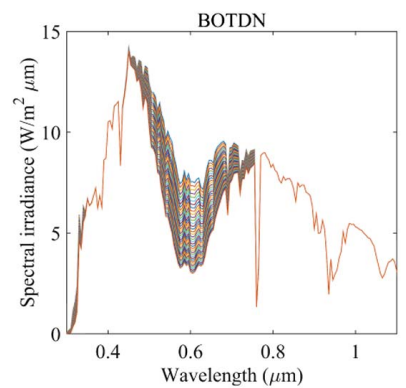

(a)

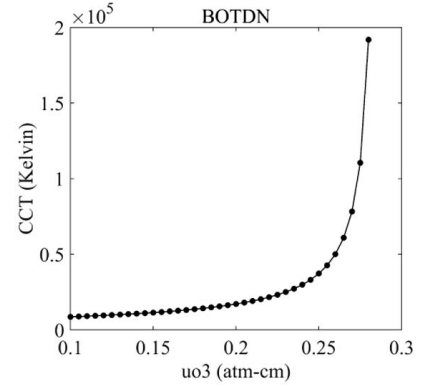

(b)
F6:1 Fig. 6. (a) Simulated daylight spectral irradiance (BOTDN) of a F6:2 typical overcast sky during twilight with different amounts of ozone F6:3 concentration. (b) The CCT of the simulated spectra as a function of F6:4

the far left-hand side of the diagram as the solar zenith angle decreases.

\section{DISCUSSION}

Now we are in a position to discuss the influence of atmospheric elements on colorimetric characteristics of outdoor illumination.

\section{A. Solar Elevation and Ozone Concentration}

The colorimetric analysis of our solar spectral irradiance showed that water vapor (uw) as well as the amount of ozone (uo3) highly influenced the CCT of solar illumination. Absolute absorption of ozone in the visible range of the spectrum is known as the Chappuis absorption bands of ozone within the spectral region 375-603 nm [34]. In this case, extremely high values of CCT obtained for daylight and skylight at twilight can be attributed to the Chappuis absorption band of ozone around $600 \mathrm{~nm}$. To represent the effect of ozone absorption visible region on CCT, a set of spectra was simulated by T at twilight for a typical overcast atmosphere with the 0.5 , nre $=6$, and ozone concentration, uo3, within irradiance of the simulated daylight. The absorption band of ozone can be observed at around $600 \mathrm{~nm}$ in Fig. 6(a) for simulated daylight under conditions with different ozone concentrations. Figure 6(b) shows that CCT of daylight drastically within the range of $0.1-0.28 \mathrm{~atm}-\mathrm{cm}$. This observation is consistent with previous research indicating that the presence of atmospheric ozone results in a bluer sky during twilight [35]. In our simulation, the chromaticity of twilight sky gets extended toward bluish color at higher amounts of ozone, namely, at uo3 $>0.3-0.35$. In common natural conditions, Lee et al. [35] found a meaningful but weak, positive correlation between ozone concentration and CCT of the twilight sky. The authors [35] observed twilight colors beyond infinite CCT in Owings, Maryland, even in instances of lower ozone concentrations. ticles as well as ozone absorption substantially contribute to the color of twilight sky. In Section 4.C, we will show that spectral ozone concentration, uo3, within the range of $0.1-0.28 \mathrm{~atm}-\mathrm{cm}$. dependence of the aerosol optical thickness can influence the color of natural illumination.

To represent a combined effect of ozone and solar elevation on color temperature, BOTDN, BOTDIR, and skylight irradiance functions were simulated under a clear sky without aerosol particles with albcon $=0.2$, uw $=0.5$, uo3 within the range of $0.05-0.4 \mathrm{~atm}-\mathrm{cm}$, and $\mathrm{sza}=0-89^{\circ}$. As presented in Fig. 7 , the $r$ CCT of BOTDN shows a drastic fall off at sza $>85^{\circ}$ when the sun is reaching the horizon. At lower amount of ozone, $r$ CCT of BOTDN started to increase at sza $\sim 50^{\circ}$ up to $\sim 85^{\circ}$. As the amount of ozone increases, $r \mathrm{CCT}$ of BOTDN at sza $>85^{\circ}$ drops to lower values, so that for uo3 $\gtrsim 0.3, r$ CCT approaches zero. This effect is even more pronounced for skylight. The $r$ CCT of skylight at uo $3 \lesssim 0.1$ continuously increases with sza, while at uo3 $>0.1$, an abrupt decrease occurs at sza $>85^{\circ}$. The direct solar irradiance is attenuated when the sun approaches the zenith. Then the radiation field is mostly governed by multiple scattering during twilight. As the wavelength decreases, scattering increases more rapidly than the absorption [36]. This observation can be explained by the Umkehr effect discovered by Götz [37].

\section{B. Aerosol Particles}

As discussed previously, the CCT of BOTDN showed a minimum of $\sim 3600 \mathrm{~K}$ observed in an atmosphere with high level of aerosol particles. Daylight measurements in Granada [12] showed a range of CCT from 3758 to $34,574 \mathrm{~K}$, including a few irradiance spectra with CCT $<5000 \mathrm{~K}$. In a hazy sky, daylight with CCT as low as $3530 \mathrm{~K}$ was reported in Rochester, New York [6]. Our simulation of daylight irradiance functions revealed that, as the concentration of aerosol particles in the atmosphere increases, daylight chromaticities extend more toward the reds along the Planckian locus. To represent the effect of aerosol particles on CCT, let us simulate irradiance functions of different solar elevations, sza $=0-89^{\circ}$, under an extreme

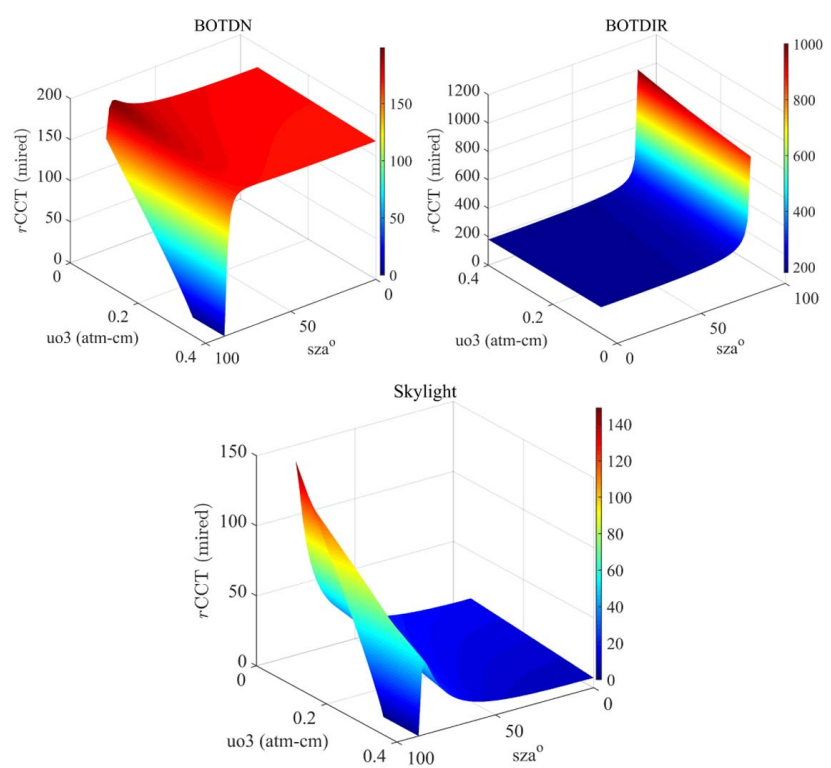

Fig. 7. $r$ CCT of BOTDN, BOTDIR, and skylight in a clear sky without aerosol particles, simulated as a function of solar zenith angle, sza, and ozone concentration, uo3. 

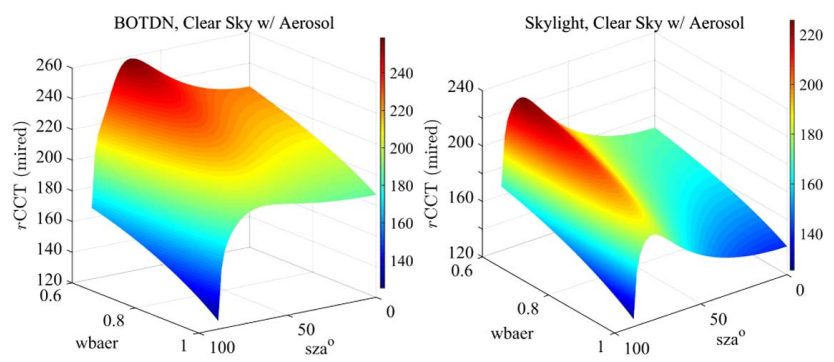

case of atmosphere with aerosol particles, where albcon $=0.05$, $\mathrm{uw}=0.25$, uo3 $=0.2$, gbaer $=0.5$, tbaer $=1$, abaer $=2$, and wbaer is selected within the range of $0.6-1$, corresponding to wlbaer at $0.55 \mu \mathrm{m}$. As illustrated in Fig. 8, at each solar elevation angle, the $r$ CCT of daylight and skylight increases with a decrease of the single scattering albedo (wbaer). It can be observed at each level of wbaer in Fig. 8 that $r$ CCT of daylight increases with sza before falling off at $\sim 75^{\circ}$. The same pattern occurred for skylight with a peak of $r$ CCT at $\sim 80^{\circ}$. A similar pattern presented in Fig. 8 was also observed for other aerosol parameters of gbaer, tbaer, and abaer. This observation indicates that the lowest possible CCT of daylight is most likely to be observed in an atmosphere with aerosol particles at sza $\sim 60-80^{\circ}$, and that of skylight at sza $\sim 80^{\circ}$. This phenomenon can be explained by the magnitude of scattered light reaching the ground level as a function of solar elevation. According to Horvath et al. [36], diffuse radiation increases with sza up to $60^{\circ}$. With sza $>60^{\circ}$, diffuse radiation falls off with an increase in aerosol particles due to greater upward scattering of radiation back to space. This pattern is also in agreement with daylight measurements in Rochester, New York, where the CCT range of $3530-4760 \mathrm{~K}$ observed at solar altitude of $8^{\circ}-30^{\circ}$ $\left(\right.$ sza $\left.=60-82^{\circ}\right)$. However, the observed daylight irradiance with CCT of $3530 \mathrm{~K}$ in Rochester, New York, is still lower than the minimum CCT of our simulated BOTDN irradiance under an atmosphere with high level of aerosol particles. It is worth mentioning that a daylight irradiance with $<3600 \mathrm{~K}$ can be observed at high levels of aerosol particles in a highly overcast sky. For instance, at sza $\simeq 70$, and wbaer $\sim 0.5-0.7$, tbaer $\simeq 1$, abaer $\simeq 2$, and tcloud $\simeq 300$, the CCT of daylight may reduce down to $3000 \mathrm{~K}$. Because the single scattering albedo (wbaer) less than 0.7 may be observed in rare conditions of dust storms and forest fires [21], our analysis suggests that observing a daylight with CCT between $\sim 3000$ and $3600 \mathrm{~K}$ is unlikely in common atmospheric conditions. This finding is in agreement with daylight measurements in Granada, Spain, where the Saharan dust is a common event and only a single daylight observation with CCT $<4000 \mathrm{~K}$ was made. This is also the case for daylight observations in Rochester, New York. Furthermore, the lowest observed CCT $\simeq 3800 \mathrm{~K}$ was reported for skylight in Granada [29], which is also close to the lowest CCT observed in our skylight irradiance at high aerosol-particle levels in the atmosphere ( $r$ CCT $\sim 260$ mired). Again, a few skylight irradiances with CCT $<4000 \mathrm{~K}$ were observed in Granada, Spain.

Fig. 8. $\quad r$ CCT of BOTDN and skylight in a clear sky with aerosol particles, simulated as a function of solar zenith angle, sza, and single scattering albedo, wbaer.
The lowest possible CCT of daylight in an atmosphere without aerosol particles was found around $5380 \mathrm{~K}$, which is close to a minimum CCT $=5400 \mathrm{~K}$ for daylight observed in Boulder, Colorado [14]. Although the maximum solar zenith angle in the daylight measurements in Boulder was $\sim 56^{\circ}$, which imposes a limit to the observed CCT, from the trend shown for daylight CCT in Fig. 3 and the chromaticity scattering in Fig. 5, the colorimetric pattern of observations in Boulder represents measurements in an atmosphere with lower aerosol particles.

\section{Green-Purple Chromaticity Shift}

As presented in Fig. 5, in an atmosphere with aerosol particles, chromaticities of daylight slightly shifted toward the purple side of the Planckian locus. This type of scattering around the locus was observed with different magnitudes in previous observations [5,6,8-12]. Nevertheless, the magnitude of the greenpurple shift reported in India [9] was greater than that observed elsewhere. In contrast, the chromaticities of daylight observed in Boulder, Colorado [14] did not show any shift toward the purple side of the locus. Previous research $[9,11]$ showed that chromaticity points tend to lie toward the purple side of the locus in a hazy sky and toward the green side in a clear sky. The green-purple shift in hazy skies was also reported by Lee [38] who attributed the effect to the spectral extinction by aerosol particles.

If the spectral extinction of aerosol particles contributes to the green-purple chromaticity shift, we ask "to what extent is such a shift governed by aerosol optical properties in common atmospheric conditions?" To answer this question, we consider two typical cases of an atmosphere with urban-industriall biomass burning and desert dust-oceanic aerosol particles with a range of optical properties reported by Dubovik et al. [19]. Table 4 shows the parameters selected to simulate the spectral irradiance functions under the two typical conditions. In this table, the spectral dependence of the optical thickness, $\tau(\lambda)$, is characterized by the Angström law [39], $\beta \lambda^{-\alpha}$, where the wavelength-independent coefficients $\alpha$ (abaer) and $\beta$ are applied across the spectrum [40]. The chromaticity scattering of BOTDN spectra simulated under these two typical conditions are illustrated in Fig. 9. The chromaticity scatterings of our simulated hemispheric daylight in an atmosphere with urban-industrial and biomass burning aerosols, shown in Fig. 9(a), are mainly located along the Planckian locus with a slight shift toward the purple side at lower CCTs. The single scattering albedo of urban-industrial and biomass burning aerosols decreases with wavelength in no dust condition [19,22]. Aerosols with higher angstrom exponent $\sim 1.5-2$ and higher optical thickness $(\tau>1)$ are strongly absorbent particles. In this case, the chromaticity of a hemispheric daylight at sza $\sim 60-80^{\circ}$ (see Fig. 8 ) in an atmosphere with absorbent particles is slightly shifted from green toward purple, particularly if absorption at middle wavelengths is relatively strong. The results shown here are in agreement with previous observations $[8,10,11,41]$ in which scattering of chromaticities around the Planckian locus was mainly observed at CCT $<\sim 10,000 \mathrm{~K}$.

In contrast, the single scattering albedo of desert dust and oceanic aerosols increases with wavelength [19,22]. Chromaticities of hemispheric daylight simulated in this 
Table 4. SBDART Parameters for Simulating Spectral Irradiance Functions in an Atmosphere with Aerosol Particles $^{a}$

$\mathrm{T} 4: 1$

T4:2

$\mathrm{T} 4: 3$

$\mathrm{T} 4: 4$

T4:5

T4:6

$\mathrm{T} 4: 7$

$\mathrm{T} 4: 8$

T4:9

$\mathrm{T} 4: 10$

\begin{tabular}{lcc}
\hline & \multicolumn{2}{c}{ Condition } \\
\cline { 2 - 3 } Parameters & Urban industrial & Desert dust \\
\hline \multirow{2}{*}{ albcon } & Biomass burning & Oceanic \\
uw & 0.2 & 0.2 \\
uo3 & 0.2 & 3.0 \\
wbaer & 0.25 & 0.25 \\
Optical & $0.91,0.87,0.85,0.83]$ & {$[0.91,0.95,0.96,0.97]$} \\
thickness & $\tau(0.44):$ & $\tau(1.02):$ \\
abaer & $0.25,0.6,0.8,1.0,1.5$ & $0.1,0.5,1.0$ \\
\hline
\end{tabular}

${ }^{a}$ With wlbaer $=0.44,0.55,0.67,0.87$, the wavelength dependence of the optical thickness, $\tau(\lambda)$, is determined by the Ångström law with an exponent of abaer. The simulation was conducted at $\mathrm{sza}=0-89^{\circ}$, with gbaer $=0.8$ across the spectrum. Chromaticities of hemispheric daylight of the oceanic atmosphere with desert dust particles represent a shift toward the green side of the Planckian locus. Such scatterings in the atmosphere with urban-industrial/ biomass burning aerosols are mainly located along the Planckian locus and slightly toward the purple side at lower CCTs.

condition, presented in Fig. 9(b), are all located above the Planckian locus. This condition is mainly different from the previous one both in terms of the spectral variation of single scattering albedo and the amount of water vapor in the atmosphere. In our simulation of a dusty atmosphere (Table 4), absorption capacity of water vapor at longer wavelengths together with lower single scattering albedo at shorter wavelengths both contribute in shifting the chromaticities toward the green side of the Planckian locus. As reported in the literature [19,20,42], there is a good deal of uncertainty in spectral variation of the single scattering albedo. Nevertheless, within a plausible range of variability of aerosol optical properties, scattering of chromaticities along the green-purple direction, shown in Fig. 9 as well as in Fig. 5, is much smaller than that observed in Delhi [9]. Although Saharan dust is a common event in southern Europe, chromaticities of daylight observed in Granada [12] are not

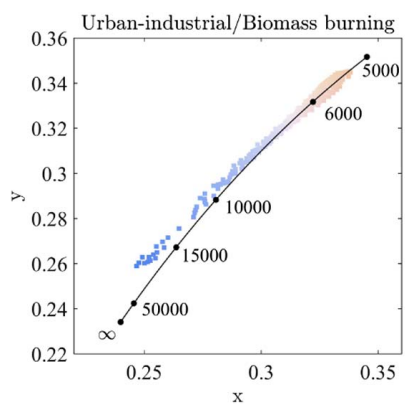

(a)

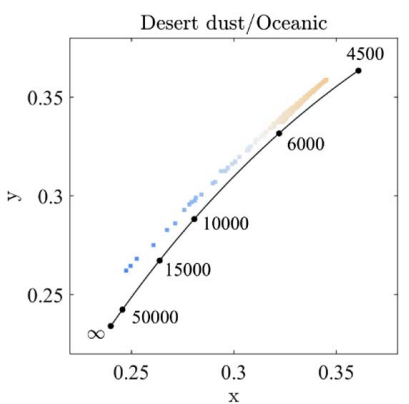

(b)
Fig. 9. CIE 1931 chromaticity diagram of hemispheric daylight simulated by parameters introduced in Table 4. (a) Chromaticities in the atmosphere with urban-industrial/biomass burning aerosols are mainly located above the Planckian locus at CCT $>\sim 10,000 \mathrm{~K}$, with a slight shift toward the purple side at lower CCTs. (b) Chromaticities of simulated daylight in the oceanic atmosphere with desert dust and higher amounts of water vapor are all located above the Planckian locus. widely scattered along the green-purple direction. The results indicate that the magnitude of the green-purple shift depends on the spectral extinction by aerosol particles as well as the amount of water vapor in the atmosphere. However, within a plausible variation of atmospheric components, we could not find evidence that the chromaticity of daylight can widely scatter along the green-purple direction. Thus, our simulation does not allow us to fully determine the origin of a wide scattering observed in Delhi [9], nor to conclude that such a wide scattering may typically be observed in nature.

\section{CONCLUSION}

In this research, the radiative transfer computer code, SBDART [16], was used to simulate spectral irradiance functions of daylight (BOTDN), sunlight (BOTDIR), and skylight within the range $0.3-1.1 \mu \mathrm{m}$, with $0.005 \mu \mathrm{m}$ intervals, under the three atmospheric conditions of clear sky without aerosol particles $(16,800$ spectra), clear sky with aerosol particles $(4,838,400$ spectra), and overcast sky (756,000 spectra). Each condition was specified by taking into account a plausible set of values for the atmospheric parameters. Although the irradiance functions simulated in this research does not cover all possible instances of downward flux across the globe, it does provide an overall view on the colorimetric specification of physical illuminations, which may be commonly observed in nature.

Colorimetric analysis of the simulated radiation demonstrated that the $r$ CCT of skylight under the three atmospheric conditions falls within the range of 0-261 mired and that of direct sunlight in the 156-1591 mired range. Direct sunlight with CCT $<1000 \mathrm{~K}$ was obtained mainly during twilight when the luminance of the direct flux is too low. Analysis of color temperature across the three conditions indicated that the $r$ CCT of daylight mainly fall within the 0-276 mired range, and the most frequent daylight CCT, depending on atmospheric conditions, was observed from 5712 to $7757 \mathrm{~K}$. The most frequent CCT for daylight in the overcast condition was observed from $\sim 6218$ up to $7757 \mathrm{~K}$, which is higher than those observed in the clear sky condition. Our analysis indicates that CCT of $6500 \mathrm{~K}$ recommended by the CIE for neutral daylight falls only within the interquartile range of CCTs for daylight in the overcast sky. This observation may question the validity of the CIE-recommended daylight as being relevant across all atmospheric conditions. We discussed that extremely high values of CCT for daylight and skylight, obtained at low sun, in an atmosphere without aerosol particles, is due to the Chappuis absorption band of ozone at $\sim 600 \mathrm{~nm}$. We found that the higher the ozone concentration in the atmosphere is and the lower the sun is elevated, the higher the CCT for daylight (skylight) illumination is obtained. However, in an atmosphere with aerosol particles, the color of a twilight sky could be influenced by the contribution of both ozone and aerosol particles.

The range of most frequent CCT for daylight in the clear sky without aerosol was found between $~ 5889$ and $6294 \mathrm{~K}$. Under this atmospheric condition, the lowest CCT was observed around $5380 \mathrm{~K}$. Introducing aerosol particles to the atmospheric model typically shifted the CCT to lower values with a minimum CCT of about $3600 \mathrm{~K}$. Although relatively 
rare in the atmosphere, the presence of higher levels of aerosol particles with the single scattering albedo (wbaer) less than 0.7 , specifically in a highly overcast sky, can lower the minimum CCT from $3600 \mathrm{~K}$. We found that the higher the aerosol particles are present in the atmosphere, the lower the minimum CCT observed. The presence of aerosols also shifted the chromaticity distributions toward the purple side of the locus, particularly at lower CCTs. As far as our simulation results suggest, spectral variation of aerosol optical extinction is critical in shifting the chromaticity of outdoor illumination, but the strength and direction of such shifts are contingent upon the concentration of water vapor and ozone concentrations. Our analysis showed that spectral daylight measured in Boulder, Colorado [14], typifies an atmosphere of low aerosol particles. In contrast, daylight measurements made in Granada, Spain [29], and Rochester, New York [6], represent atmospheres with dust and aerosol particles of different types. Investigating spectral components of the simulated radiations and exploring the effect of aerosol particles in an overcast sky on colorimetric specifications of solar irradiance are topics for future research.

2 Funding. The Andalusian Regional Government (P10RNM-6299, P12-RNM-2409); The Spanish Ministry of Science and Technology (CGL2013-45410-R); The EU via the ACTRIS project (EU INFRA-2010-1.1.16-262254); The Spanish Ministry of Economy and Competitiveness (DPI2011-23202).

Acknowledgment. The authors would like to thank the two anonymous reviewers for their constructive comments, which substantially improved the manuscript.

\section{REFERENCES AND NOTES}

1. C. G. Abbot, F. E. Fowle, and L. B. Aldrich, "The distribution of energy in the spectra of sun and stars," Smithsonian Misc. Collections 74, 1-30 (1923).

2. A. H. Taylor and G. P. Kerr, "The distribution of energy in the visible spectrum of daylight," J. Opt. Soc. Am. 31, 3-8 (1941).

3. D. B. Judd, D. L. MacAdam, and G. Wyszecki, "Spectral distribution of typical daylight as a function of correlated color temperature," J. Opt. Soc. Am. 54, 1031-1040 (1964).

4. Spectral distributions measured by Budde, H. W., Unpublished Data.

5. S. T. Henderson and D. Hodgkiss, "The spectral energy distribution of daylight," Br. J. Appl. Phys. 14, 125-131 (1963).

6. H. R. Condit and F. Grum, "Spectral energy distribution of daylight," J. Opt. Soc. Am. 54, 937-940 (1964).

7. CIE, "Colorimetry (Official Recommendations of the International Commission on Illumination), CIE Publication No. 15 (E-1.3.1). Bureau Central de la CIE, Paris." (1971).

8. Y. Nayatani and G. Wyszecki, "Color of daylight from north sky," J. Opt. Soc. Am. 53, 626-629 (1963).

9. S. R. Das and V. D. P. Sastri, "Typical spectral distributions and color for tropical daylight," J. Opt. Soc. Am. 58, 391-398 (1968).

10. G. T. Winch, M. C. Boshoff, C. J. Kok, and A. G. du Toit, "Spectroradiometric and colorimetric characteristics of daylight in the southern hemisphere: Pretoria, South Africa," J. Opt. Soc. Am. 56, 456-459 (1966).

11. E. Dixon, "Spectral distribution of Australian daylight," J. Opt. Soc. Am. 68, 437-450 (1978).

12. J. Hernández-Andrés, J. Romero, J. L. Nieves, and R. L. Lee, Jr., "Color and spectral analysis of daylight in southern Europe," J. Opt. Soc. Am. A 18, 1325-1335 (2001).
13. G. Wyszecki and W. S. Stiles, Color Science: Concepts and Methods, Quantitative Data and Formula (Wiley, 1982).

14. Z. Pan, G. Healey, and D. Slater, "Global spectral irradiance variability and material discrimination at Boulder, Colorado," J. Opt. Soc. Am. A 20, 513-521 (2003).

15. W. E. K. Middleton, "The color of the overcast sky," J. Opt. Soc. Am. A 44, 793-798 (1954).

16. P. Ricchiazzi, S. Yang, C. Gautier, and D. Sowle, "SBDART: A research and teaching software tool for plane-parallel radiative transfer in the Earth's atmosphere," Bull. Am. Meteorol. Soc. 79, 2101-2114 (1998).

17. K. Stamnes, S. Tsay, W. Wiscombe, and K. Jayaweera, "Numerically stable algorithm for discrete-ordinate-method radiative transfer in multiple scattering and emitting layered media," Appl. Opt. 27, 2502-2509 (1988).

18. J. Li and K. Shibata, "On the effective solar pathlength," J. Atmos. Sci. 63, 1365-1373 (2006).

19. O. Dubovik, B. Holben, T. F. Eck, A. Smirnov, Y. J. Kaufman, M. D. King, D. Tanré, and I. Slutsker, "Variability of absorption and optical properties of key aerosol types observed in worldwide locations," J. Atoms. Sci. 59, 590-608 (2002).

20. H. Lyamani, F. J. Olmo, and L. Aldos-Arboledas, "Long-term changes in aerosol radiative properties at Armilla (Spain)," Atmos. Environ. 38 5935-5943 (2004).

21. D. Goto, T. Takemura, T. Nakajima, and K. V. S. Badarinath, "Global aerosol model-derived black carbon concentration and single scattering albedo over Indian region and its comparison with ground observations," Atmos. Environ. 45, 3277-3285 (2011).

22. J. Bi, J. Huang, Q. Fu, X. Wang, J. Shi, W. Zhang, Z. Huang, and B. Zhang, "Toward characterization of the aerosol optical properties over loess plateau of northwestern china," J. Quant. Spectrosc. Radiat. Transfer 112, 346-360 (2011).

23. S. Peyvandi, S. H. Amirshahi, J. Hernández-Andrés, J. L. Nieves, and J. Romero, "Spectral recovery of outdoor illumination by an extension of the Bayesian inverse approach to the Gaussian mixture model," J. Opt. Soc. Am. A 29, 2181-2189 (2012).

24. S. Peyvandi, J. L. Nieves, and A. Gilchrist, "On the information content along edges in trichromatic images," in C/C21, 21st Color and Imaging Conference, Albuquerque, New Mexico (2013), pp. 236-239.

25. D. K. Prasad and L. Wenhe, "Metrics and statistics of frequency of occurrence of metamerism in consumer cameras for natural scenes," J. Opt. Soc. Am. A 32, 1390-1402 (2015).

26. S. M. C. Nascimento, K. Amano, and D. H. Foster, "Spatial distributions of local illumination color in natural scenes," Vis. Res. 120, 39-44 (2016).

27. O. Packer and D. R. Williams, "Light, the retinal image, and photoreceptors," in The Science of Color, S. K. Shevell, ed. (Elsevier, 2003), 2nd ed.

28. A. R. Robertson, "Computation of correlated color temperature and distribution temperature," J. Opt. Soc. Am. A 58, 1528-1535 (1968).

29. J. Hernández-Andrés, J. Romero, and R. L. Lee, "Colorimetric and spectroradiometric characteristics of narrow-field-of-view clear skylight in Granada, Spain,” J. Opt. Soc. Am. A 18, 412-420 (2001).

30. C. A. Gueymard, "Parameterized transmittance model for direct beam and circumsolar spectral irradiance," Sol. Energy 71, 325346 (2001).

31. V. D. P. Sastri and S. B. Manamohanan, "Spectral distribution and colour of north sky at Bombay," J. Phys. D 4, 381-386 (1971).

32. J. Hernández-Andrés, R. L. Lee, and J. Romero, "Calculating correlated color temperatures across the entire gamut of daylight and skylight chromaticities," Appl. Opt. 38, 5703-5709 (1999).

33. R. L. Lee and J. Hernández-Andrés, "Measuring and modeling twilight's purple light," Appl. Opt. 42, 445-457 (2003).

34. J. Brion, A. Chakir, J. Charbonnier, D. Daumont, C. Parisse, and J. Malicet, "Absorption spectra measurements for the ozone molecule in the 350-830 nm region," J. Atmos. Chem. 30, 291-299 (1998).

35. R. L. Lee, W. Meyer, and G. Hoeppe, "Atmospheric ozone and colors of the Antarctic twilight sky," Appl. Opt. 50, F162-F171 (2011). 
36. H. Horvath, L. A. Arboledas, F. J. Olmo, O. Jovanović, M. Gangl, W. Kaller, C. Sánchez, H. Sauerzopf, and S. Seidl, "Optical characteristics of the aerosol in Spain and Austria and its effect on radiative forcing," J. Geophys. Res. 107, 4386 (2002).

37. F. W. P. Götz, "Zum strahlungsklima des spitzbergen sommers," Gerlands Beitraege zur Geophysik 31, 119-154 (1931).

38. R. L. Lee, "Tropospheric haze and colors of the clear daytime sky," Appl. Opt. 54, B232-B240 (2015).

39. A. Angström, "On the atmospheric transmission of sun radiation and on dust in the air," Geografiska Annaler 11, 156-166 (1929).
40. L. Aldos-Arboledas, H. Lyamani, and F. J. Olmo, "Aerosol size properties at Armilla, Granada (Spain)," Q. J. R. Meteorol. Soc. 129, 13951413 (2003).

41. A. Radmanesh, S. H. Amirshahi, and S. Peyvandi, "Spectral distribution of daylight in Tehran, Iran," in Proc. 12th Congress of the International Colour Association, L. MacDonald, S. Westland, and S. Wuerger, eds. (AIC, 2013), p. 230.

42. V. E. Cachorro, P. Durán, R. Vergaz, and A. M. de Frutos, "Columnar physical and radiative properties of atmospheric aerosols in north central Spain,” J. Geophys. Res. 105, 7161-7175 (2000). 


\section{Queries}

1. AU: Please check footnote text.

2. AU: The funding information for this article has been generated using the information you provided to OSA at the time of article submission. Please check it carefully. If any information needs to be corrected or added, please provide the full name of the funding organization/institution as provided in the FundRef Registry (http://www.crossref.org/fundref/fundref_registry.html).

3. AU: Please use a page number range for the reference. 